\title{
MANUFACTURING IN SOUTH AFRICAN MICROENTERPRISES
}

Claudia Manning and Angela Pinky Mashigo

\section{MICROENTERPRISES IN THE SOUTH AFRICAN ECONOMY}

The combination of declining growth and rising unemployment has impacted substantially on the size of the microenterprise sector in South Africa ${ }^{1}$. The Central Statistical Service estimated in 1990 that 2.7 million people (that is, 24 per cent of the labour force) were active in what they termed the 'informal sector'. A closer examination of the characteristics of this 'sector', however, reveals that the vast majority of activities are in the trade and services sectors and are oriented towards subsistence and survival. Indeed, most studies have concluded that there is a dearth of manufacturing in South African microenterprises.

The study upon which this article is based attempted to develop a clearer picture of the microenterprise manufacturing sector in South Africa, raising questions on the overall viability of manufacturing in microenterprises, the employment creation possibilities in these enterprises and the potential for certain segments of the sector to contribute towards enhancing the productivity and competitiveness of the South African economy. We begin by examining some of the factors explaining the dearth of manufacturing activities in microenterprises, and conclude by suggesting some of the main elements of a policy framework for promoting manufacturing in microenterprises.

\section{MANUFACTURING IN MICROENTERPRISES}

Most studies on informal and small scale economic activity in South Africa have commented on the paucity of small manufacturers. Liedholm's (1991) survey of microenterprises in two South African townships found that 16.9 per cent of enterprises surveyed were involved in manufacturing. This

\footnotetext{
1 The South Africa economy has experienced a sharp fall in growth rates over the past decade. Official South African unemployment estimates are recognized to be unreliable. It is widely accepted that the real figure is in excess of 40 per cent.
}

compares very poorly with a wide range of other developing countries, where manufacturing tends to comprise a considerably higher proportion of microenterprise activity. Thus, for example, comparable figures show that manufacturing comprises the following percentage of microenterprise activity: 36 per cent in Maseru (Lesotho); 32 per cent in Abidjan (Ivory Coast); 47 per cent in Freetown (Sierra Leone); 32 per cent in the Niger city of Maradi; 23.5 per cent in Mexico in 1987; and 26.7 per cent in Columbia in 1984 (Charmes 1991).

\subsection{Explanations for the low incidence of manufacturing in microenterprises in South Africa}

Most explanations of why so few microenterprises in South Africa engage in manufacturing activities focus on the restrictive Apartheid policies. These not only legally prohibited Blacks from becoming entrepreneurs, but also systematically deprived them of obtaining any of the education, skill and experience essential for the emergence of dynamic entrepreneurship, and especially for the emergence of a skilled class of manufacturers. The impact of repressive regulation cannot be under-estimated: Blacks were forbidden by law from engaging in manufacturing businesses, and access to business premises was strictly regulated with the explicit intention of preventing Blacks from operating businesses in 'White' areas. It was only in 1979 that official policy shifted from preventing Blacks from having manufacturing businesses ${ }^{2}$.

A further explanation is to be found in the structure of the South African economy, in particular the high levels of concentration of capital. As Lewis (1993) has found, oligopolistic control over certain markets by the large conglomerates is rife, as

\footnotetext{
${ }^{2}$ Rogerson and da Silva (1987) have clearly documented the development of legal barriers repressing and finally eliminating industrial activity amongst Blacks in the Witwatersrand region, during the period from the 1940 s till the 1960s. They write: 'The assault on Black smallscale manufacturers operating in the urban environment... commenced in the 1930 s and was concluded in the 1950s'. (1987:8)
} 
is collusion, predatory pricing, and the tendency for large corporations to absorb dynamic independent smaller enterprises. These factors represent significant barriers to entry into many product markets.

\section{RESEARCH RESULTS}

\subsection{Why do individuals enter the}

\section{microenterprise manufacturing sector?}

This issue is frequently disputed in the literature. Some observers take the position that individuals choose to enter the informal or small enterprise sector, whilst others argue that it is desperation which motivates entry into these activities. We would argue that the real cause of this dispute lies in the fact that different analysts are observing different segments of the microenterprise sector, each possessing distinctive characteristics. Whilst unskilled, impoverished, unemployed workers are likely to be 'pushed' into the informal sector, the more skilled, more affluent individuals may be attracted or 'pulled' into beginning their own businesses by the prospect of enhanced incomes. Thus both analyses - that entry is motivated by poverty or by entrepreneurial fervour - may be accurate, based as they are on different realities. Our research into clothing enterprises in the Western Cape - conducted in the African townships of Cape Town found that most of the entre-preneurs had been unemploved. and it was their inability to find employment which motivated them to start their own enterprises $^{3}$. Consequently, many of these interviewees stated their preference to enter 'formal' employment as paid employees. Our research into the lower value segment of the informal clothing industry in Durban revealed very similar characteristics amongst entrepreneurs, who also tended to be poor, unskilled and poorly educated. However, other manufacturers - who were producing highvalue, high cost garments; cottage furniture; electronically controlled burglar gates for relatively affluent clients - had willingly left their previous employment in the hope of improving their incomes. For this segment of industries, it was 'entrepreneurial' motivation which had spurred them to start their own enterprises. Despite problems in the enterprises' performance, almost all stated no desire to give up self-employment. These findings thus

${ }^{3}$ Mashigo's study into 25 clothing manufacturers found that 45 per cent of interviewees had begun their enterprise due to failure to find alternate employment. Of the rest, confirm international observations that individuals' entry into and location in the informal or small enterprise spectrum is determined by a range of different factors - unemployment, skill and education of the entrepreneur, geographical location, social factors such as class, race, and gender - and that individuals with differing endowments will enter the industry for different reasons.

\subsection{The role of the microenterprise manufacturing sector in South African markets}

Because of the diverse character of the microenterprise manufacturing sector, we found that enterprises play a number of roles. Firstly, they produce cheap goods for the poor. Secondly, they contribute towards lowering the costs of production by acting as subcontractors to the rest of industry. And thirdly, they produce high value, high quality goods for niche markets. Thus contrary to prior expectations, we found that microenterprises are operating in a wide range of markets. Entrepreneurs' location in each of these markets is clearly influenced by a number of factors: technical and managerial skill; relationship with the formal financial institutions; experience accumulated in the 'formal' sectors of industry and access to networks potentially offering support. Apartheid policies systematically deprived Blacks of access to a whole range of experiences, information and markets vital to building a successful entrepreneurial tradition. These included access to formal education and skills; access to position of influence and authority in firms and the development of networks of support in the business community. Thus African-owned microenterprises are typically located in the lowest value, poorest quality, least lucrative segments of the manufacturing sectors.

Because of the vast differences in the characteristics and constraints of each of the segments of microenterprises, we will briefly profile each of them.

\subsubsection{Low end of the market}

Manufacturers located in this end of the market are usually single-person operations, or employ only one or two workers. They tend to have started the business using personal or family
22.7 per cent of respondents wanted to increase their husband's income, and 13.6 per cent reported the desire for greater independence as the prime motivating factor. 
savings. They are usually equipped with only rudimentary technical skills; lack extensive personal exposure to 'formal' industry; and use the simplest technology available for that industry. ${ }^{4}$

The dominant characteristic of microenterprise manufacturing in South Africa is the extreme market concentration prevalent in the low end of the market. Large numbers of entrepreneurs crowd into limited markets, producing identical goods for sale at similar prices. This applies to the thousands of garment manufacturers making simple cotton dresses of the same design and fabric (for sale for less than $£ 4$ each), as well as to the vast numbers of metal benders making security bars and gates. Diversification into new products ranges or markets is constrained by three principal factors: lack of technical skill to produce more sophisticated products; lack of access to capital to finance expansion into new products ranges; and reluctance to take the risks implied by entering into uncertain markets.

Access to product markets is another debilitating factor constraining these manufacturers from growing. Firstly, these entrepreneurs are restricted to manufacturing for low-income consumers in Black townships, and are unable to penetrate more affluent markets. The isolation of most of these manufacturers from linkages with the rest of the industry results in failure to procure subcontracts - considered by most of these interviewees to be a major objective because of the stability of production and potential for networking implied by access to subcontracts. Secondly, manufacturers are dependent on referral by satisfied customers as their main marketing instrument. This leads to instability in production since manufacturers are forced to wait for individuals to place orders before engaging in production (much in the way that traditional seamstresses operated). Failure to procure orders results in long periods of inactivity, forcing entrepreneurs to put employees on short-time.

Another constraint which has a serious impact on these manufacturers is their customers' reliance

${ }^{4}$ In the case of garment manufacturers, this would be a second-hand domestic sewing machine (either electric or hand-driven). Metal benders would use a basic welding machine. on credit. Most manufacturers give their customers between 30 and 90 days interest-free credit, causing serious cash-flow problems. ${ }^{5}$

\subsubsection{Middle to upper end of the market}

Those manufacturers with more developed skills usually acquired through extensive experience in the 'formal' sectors of industry, whether that be as a semi-skilled worker or an artisan - as well as greater access to capital are able to begin manufacturing for relatively more secure segments of the market. Thus manufacturers in the garment and furniture industries are able to obtain contracts from the larger manufacturers and retailers (either on a cut-makeand-trim or a completeorder basis), allowing them to expand their production and workforce. Opportunities for diversification into new product lines, the use of alternative technologies and entrance into newer, more affluent markets are thus enhanced. Hoever, a number of major constraints remain.

The first is the relationship between the manufacturer on the one hand and the retailers and subcontracting principals on the other. Although these manufacturers are relatively more secure in that they have succeeded in accessing a larger market (via the retailers or contractors), this relationship is also a source of conflict in that smaller manufacturers tend to be extremely vulnerable to the dictates of the more powerful partners. Throughout our research we consistently encountered manufacturers complaints against retailers' excessive power over them. In the garment industry the main criticism was about the low prices set by the retailers, which severely squeezed their profit margins. The main objection of the furniture manufacturers, on the other hand, was about the terms of payment dictated by the retailers, that is, that they often had to wait for payment from the retailers for as long as 120 days. The impact of this delay on the firm's cash flow is obvious. In addition, a host of other criticisms were levelled against the retailers for unfair practices regarding cancellation of orders; changing conditions of contracts without due notice, and so on.

\footnotetext{
${ }^{5}$ For example, one furniture manufacturer was obliged to give 12 months credit to his customers, since extensive credit arrangements are customary in the South African furniture industry. Unlike the furniture retailers however, this entrepreneur found it impossible to charge interest, and was thus continually incurring losses, as inflation rates in South Africa have exceeded 12 per cent in recent years.
} 
Linked to this issue of the vulnerability of the manufacturer to the larger firms is the question of the manufacturers' access to working capital. Not only do manufacturers have to wait for several months for payment after completion of a contract, but access to capital to finance the completion of orders is also difficult, especially if capital is needed for short term use. The hostility of the South African financial sector to microenterprises - and indeed to small- and medium- sized enterprises - is widely recognized. Collateral requirements amongst most institutions - including those that have been specifically set up to support small and microenterprises, such as the Small Business Development Corporation (SBDC) - are often prohibitively high, impacting most substantially on Black borrowers who have historically been deprived of capital. The result is that Black entrepreneurs tend to be capital constrained. 6 This raises the issue of how financial institutions could become more flexible in their lending policies.?

\subsection{Constraints on graduating into more lucrative markets}

One of the indications of the dynamism of manufacturing within microenterprises is the degree to which firms can become more dynamic - diversify their product lines, enter into new markets and expand their businesses. Our study found that South African microenterprises display remarkably little dynamism. Once entrepreneurs locate themselves in particular segments of the market, it is uncommon for them to enter into different markets or to diversify into different products lines. The result of this tendency is that vast numbers of entrepreneurs are confined to lowincome markets and competitive pressures are high. Many of the chief constraints inhibiting this movement have been discussed in the article thus far inadequate skill; lack of access to more lucrative markets; lack of access to capital. However, a number of other constraining factors are also worthy of mention:

- Physical infrastructure tends to be extremely limited in Black townships - inadequate telephones, electricity, and roads make communication and production difficult.

6 It is rare to find microenterprises being accorded even standard overdraft facilities - a facility which is common to most established firms.

${ }^{7}$ Whilst access to working capital is undoubtedly a constraint for most microentrepreneurs, those who are presented with
- Lack of appropriate institutional support: most support agencies dealing with microenterprises tend to be biased in favour of distributive rather than productive activities. This applies both to financial services as well as to training services. In addition, institutions offering support for microenterprises are highly fragmented, with co-operationbeing extremely uncommon.

Institutions ostensibly serving the interests of the business community in South Africa tend tobelargely biased in favour of the larger firms, with services being designed with the more sophisticated business in mind. This is the case with the Industrial Development Corporation (IDC) (which has until recently only granted loans to larger firms) and the South African Foreign TradeOrganization (SAFTO) (which has provided institutional support to promote the exports largely of the bigger firms and corporations).

The high levels of concentration in South African industry raise serious obstacles preventing new, smaller firms from entry into many markets. Although this impacts differentially on firms in different sectors, extensive ownership links between suppliers, manufacturers and retailers tend to result in a singularly uncompetitive environment, hostile to smaller firms.

The strong emphasis on formal accreditation of skills discriminates against those entrepreneurs who are equipped with the skills to perform particular functions, but who lack the formal qualifications to demonstrate this.

- The racial character of networks. South Africa's Apartheid legacy pervades all aspects of South African life - not least the social networking of business people. Networks tend to be racially exclusive, since most of the economic power is concentrated amongst the White community, White networks serve to retain power and influence amongst members of the network that is excluding nonWhites from entry.

- It will be obvious to any observer of South Africa that the current political environment acts as one of

export possibilities are faced with additional constraints in accessing export finance. Although this problem is likely to affect very few microenterprises, it remains an important obstacle for thosedynamicmicroenterprises in niche markets who may be in a position to export. 
the most significant destabilizing factors for the growth of businesses of any size and type. The violence and crime which pervades townships impacts most strongly on smaller firms located in townships, who find that they are easy targets. Political stability is clearly one of the most critical preconditions for the growth of the South African economy.

\section{A FRAMEWORK FOR POLICY}

There are three broad objectives motivating support for the microenterprise manufacturing sector in South Africa:

- For equity reasons, to facilitate small Black business' access into the largely White South African manufacturing sector. Although we need to be wary of pigeon-holing Black business people exclusively into microenterprises, it is the current reality that this sector has the lowest barriers to entry to newcomers.

To explore opportunities for enhancing the competitiveness of the South African economy by raising activity within the microenterprise manufacturing sector. This requires policy makers to identify potentially competitive segments of the sector, and to attempt to minimize constraints inhibiting these firms from growth.

To enhance the employment generating capacity of the microenterprise manufacturing sector.

The following are some of the major issues which must form part of a new policy of support for the microenterprise manufacturing sector.

\subsection{Financlal services}

A range of different financial services are required to support the varied financial needs of microenterprises. Their diverse needs necessitate the involvement of a wide range of institutions - the banking system to facilitate easier access to capital; NGOs to facilitate borrowers' access to smaller (mini) loans; the Development Finance Institutions (such as the SBDC, DBSA, and the IDC) to be less risk-averse.
- It is imperative that capital from the formal financial institutions becomes more accessible to small businesses. Using a combination of incentives and sanctions, banks must be pressurized to change their policy regarding loans to small businesses and NGOs servicing small businesses. ${ }^{8}$ This requires fundamental changes in the corporate culture of banking institutions, one example of which is the recognition of non-tangible forms of collateral such as debt owed in stokvels (informal lending networks in Black townships).

As many of them already recognize, NGOs should try to become more cost-effective, so that they are able to serve a wider number of clients. Evaluating their cost structures to eliminate inefficiencies may contribute towards this, as will a system which combines loans with client's savings. Whilst these measures will not allow NGOs to be totally self-financing, it will facilitate more efficient use of grants and loans handled by NGOs.

- The key government agent responsible for small business development - the SBDC - must be fundamentally restructured. Its board, executive committee and policy approach must reflect a new set of priorities. The SBDC must be subjected to an independent enquiry to assess its past, current and future contribution to SME development.

\subsection{Training support}

It is vital that training programmes be designed to address the skills constraints afflicting large numbers of entrepreneurs, allowing them to upgrade their skills and graduate into more lucrative markets and diversify their product lines. Adequate response to the need for skill enhancement in the sector requires the active participation and co-operation of many different agents - government, the private and NGO sectors. Yet this is severely lacking at present. The role of the industry training boards is especially crucial for manufacturers. It is imperative that the various industry training boards are re-organized to make the vast resources and skills in the boards available to a wider range of entrepreneurs than currently being served. ${ }^{9}$
${ }^{8}$ By using NGOs to mediate between banks and borrowers, they can reduce transaction costs - one of the major factors inhibiting banks from lending to microenterprises.
9 The industry training boards are strongly criticized for only serving the interests of the larger, resource-rich and powerful firms in their industries. 


\subsection{Relationship to retailers and subcontracting principals}

The relationship between retailers and manufacturers - in particular the vulnerability of manufacturers at the hands of retailers and subcontracting principals - arose repeatedly in our research as a serious obstacle to many microenterprises' growth. This raises the question of the role of business associations - associations of manufacturers in particular sectors- in defending the interests of their members, in particular in setting guide-lines regarding terms of payment. Whilst larger manufacturers tend to belong to such associations, this is rarely the case for microenterprises. This isolation consequently enhanced their vulnerability and lack of bargaining power.

The relationship between subcontractors and the subcontracting principal also requires attention, with the specific terms of the contract warranting closer scrutiny. Emulation of other countries experiences in attempting to provide more security for subcontractors may be considered. In Korea, for example, the Fair Transaction in Subcontracting Act was passed to redress the disadvantages facing SMEs entering into subcontracting relationships with more powerful large firms.

\subsection{Infrastructural support}

As Bloch pointed out in the case of the South African furniture industry (Bloch 1993), sectoral agglomerations of firms are widespread. Yet these are rarely recognized as such, and consequently fail to attract significant support from local and regional institutions. Such neglect must be reviewed in the new regional development policies being formulated, and consideration must be given to the role of local institutions in dynamizing these agglomerations, potentially impacting on the vibrancy of the local economy.

The inadequacy of existing institutions in supporting microenterprises and smaller firms from penetrating export markets has been referred to in the article. This issue calls for institutions such as SAFTO to be restructured so as to better serve the needs of smaller firms seeking to enter export markets.

\section{INDUSTRIAL AND TRADE POLICY}

Current trade policy provides incentives for the export of manufactured goods, but has thus far failed to stimulate exports of smaller firms. This is largely due to the nature of current trade policy, which sets as its specific objective the removal of anti-export biases, but which assumes (erroneously) that all firms have the infrastructure to export once these biases are removed. If products from micro-, small- or medium-sized firms are to successfully penetrate export markets, it is necessary that there is a much closer integration of trade policy and industrial policy - the latter calling for a much wider range of support mechanisms to stimulate dynamism in small firms. Networks of microenterprises may have to be encouraged (as occurs in Italy and elsewhere) to assist this extension of sales to foreign markets.

\section{CONCLUSIONS}

The economic imperatives of development in South Africa necessitates the stimulation of the microenterprise manufacturing sector. Yet there are no quick-fix solutions to the problem of how this is to be done. The relaxation of racist Apartheid regulations and the gradual movement of the country towards a political settlement will contribute towards removing some of the obstacles facing these entrepreneurs, and create a less volatile environment in which top operate. However, many other constraints - such as skill inadequacies and low purchasing power of Black consumers - can only be addressed in the medium to long term.

Any discussion of policy formulation for the sector must focus on the appropriate institutions for implementation of policy. There are clearly a wide range of issues that are most adequately addressed by government agencies (such as for regulation; infrastructure development; providing incentives for investment, and so on); the financial community (selective preferential treatment for microenterprises); the broader business community (subcontracting; market access); as well as NGOs (skill development, micro-loans). Yet a number of measures are best initiated at the level of the microenterprise community itself, such as networking between firms, information gathering and so on. What this suggests is that a comprehensive strategy for microenterprise support needs to specify the various roles that a number of different agencies might play. Since NGOs are likely to play a central role in such a strategy, careful attention must be given to 
the varied needs of the microenterprise sector. Here the lessons from other developing countries must be absorbed in order to avoid the pitfalls into which many of those countries' NGOs have fallen.

Finally, which actors ought to be involved in the process of policy formulation? One of the exciting developments in South Africa at present is the emergence of regional development fora, bringing together all the major political and economic stake-

\section{REFERENCES}

Central Statistical Services, 1990, Department of Statistics, Pretoria

Charmes, J., 1990, 'A critical review of concepts, definitions and studies in the informal sector' in Turnham, Salome and Schwarz (eds), The Informal Sector Revisited, Paris: OECD

Hirschowitz, R., 1991, 'NTB/HRSC investigation into training for the informal sector', Pretoria: HSRC

Joffe, A., Kaplan, D., Kaplinsky, R., and Lewis, D., 1993, 'A framework for industrial revival in South Africa', unpublished Industrial Strategy Project Directors' Report

Lewis, D., 1993, 'Markets, ownership and industrial competitiveness' unpublished paper prepared for the Industrial Strategy Project

Liedholm, C., 1991, 'Small scale enterprises in Mamelodi and Kwazakhele townships, South Africa: survey findings', Gemini Technical Report No 16

Lubell, H., 1991, The Informal Sector in the 1980s and 1990s, Development Center Studies, Paris: OECD

Manning, C., 1992, Manufacturing in the informal sector an evaluation of some international experiences. Policy holders (including the ANC, Cosatu, the civics, business and government), to formulate joint development strategies on a number of fronts, including small business development. It is envisaged that under the auspices of each regional development forum, regions will be in a position to emerge with the elements of a concrete strategy for microenterprise support, albeit under the general framework set by the National Economic Forum.

Implications for South Africa', MPhil thesis, IDS, University of Sussex

Manning, C., and Mashigo, P., 1993, 'Manufacturing in microenterprises in South Africa', Research Report to the Industrial Strategy Project, Cape Town: UCT

Mashigo, A., 1992, 'Informal manufacturers in South Africa: the case of wood-workers and metal workers in the Cape Flats' paper presented to the Industrial Strategy Project Workshop, November 1992

Preston-Whyte, E., and Rogerson, C., (eds), 1991, South Africa's Informal Economy, Cape Town:Oxford University Press

Regnier, P., 1992, 'Small business and industrialization in South Korea', Asia Pacific Joumal of Management, Vol 9 No 1

Rogerson, C.M., and da Silva, 1987, Urban Small Scale Industry on the Witwatersrand: Emergence, Destruction and Revival, Dept of Geography and EnvironmentalStudies, University of Witwatersrand

Schacter, M., 1992,Microentrepreneurship in South Africa: The Impact of Regulation and Support Services, Washington: World Bank 